ISBN 978-981-11-7861-0

Proceedings of 2018 the 8th International Workshop on Computer Science and Engineering

(WCSE 2018)

Bangkok, 28-30 June, 2018, pp. 161-165

doi: $10.18178 /$ wcse.2018.06.029

\title{
Research on TCAS Component-Level Circuit Fault Diagnosis Expert System
}

\author{
Xiaomin Xie ${ }^{1}$, Fan Zhang ${ }^{2}$, Yong Zeng ${ }^{1}$, Lingling Zhong ${ }^{1}$ \\ ${ }^{1}$ Institute of Electronic Communication Engineering, Anhui Xinhua University, Hefei 230088, China \\ ${ }^{2}$ Research Department, Anhui Xinhua University, Hefei 230088, China
}

\begin{abstract}
Accord to that fault diagnosis analysis of TCAS processor of airborne electronic equipment, a fault diagnosis expert system scheme based on component-level circuit is proposed. The scheme mainly carries out circuit fault diagnosis from the establishment of knowledge database and reasoning diagnosis mechanism. In the aspect of knowledge database building, SQL server language is used to build the database. In the aspect of reasoning and diagnosis mechanism, a hybrid reasoning mechanism based on the combination of case-based reasoning subsystem and fault tree reasoning subsystem is proposed, and the interpretation mechanism and self-learning mechanism of expert system fault library are established. According to TCAS fault phenomenon, the expert system can quickly and accurately diagnose the cause of the fault and give the corresponding troubleshooting plan, so as to accurately position the fault diagnosis to the component-level and achieve the purpose of depth diagnosis. Through the diagnosis example of TCAS data processor, the effect of positioning fault diagnosis to component-level is achieved.
\end{abstract}

Keywords: component-level, circuit fault diagnosis, expert system.

\section{Introduction}

At present, most civil aviation electronic equipment maintenance departments and enterprises of civil aviation airborne electronic system automatic test belongs to the board-level test, to a large extent, limits the airborne electronic system and board-level maintenance. TCAS is the abbreviation of traffic alert collision avoidance system in English, namely traffic warning collision avoidance system. TCAS can test and repair the component level depth of the failure board. TCAS can improve the level of fault diagnosis[1-2] and play the role of maintenance expert. Will greatly save maintenance costs and maintenance time, reduce spare air materials, greatly improve the economic benefits of airlines.

\section{Fault Analysis of TCAS Processor}

TCAS processor mainly includes 34 chip pins, of which CPU is the core component. The following is an example of CPU fault diagnosis and analysis.

(1) Tested element: CPU chip.

(2) Computer control system: using industrial PC. The test software runs on industrial computer to control the test process. At the same time equipped with the necessary disk drive, CRT display, keyboard, printer and other external equipment as a man-machine communication and information output device.

(3) Bus system: PCI local bus is adopted. The maximum bus transfer rate is $132 \mathrm{MB} / \mathrm{s}$, independent of the processor's 32-bit bus structure.

(4) Signal generation system/data acquisition system: digital I/O parallel interface chip is adopted. This kind of chip can be used to select the data port, the transmission direction of the port and the method of exchanging information with CPU.

(5) The tested unit interface adapter: uses the latch and state flip-flop gating circuit connected with the interface chip to program by using the inquiry input-output principle.

+ Corresponding author. Tel.: +18909699265 , + 18154112560; fax: +0551-65872323.

E-mail address: 357106305@qq.com; salas0527@163.com. 
The system hardware block diagram designed with CPU as diagnostic element is shown in fig.1.

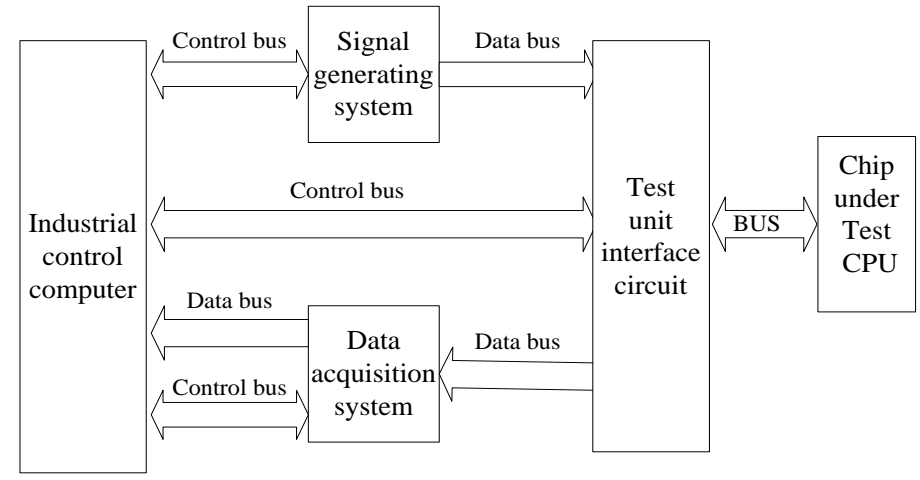

Fig. 1: Hardware block diagram of CPU fault diagnosis system.

\section{Overall Design of TCAS Fault Diagnosis Expert System}

The expert system [3-8] obtains the fault phenomenon information through the man-machine interface, and stores it in the global database with a certain structure. The inference engine finds this information in the global database and solves it accordingly. Firstly, it searches the case library of knowledge base to find the cases which meet certain conditions, and saves them to the global database. If one is found, the direct outgoing line is obtained; if more than one is found, one of the cases is allowed to be outgoing line according to the corresponding conflict resolution strategy. Then the diagnosis result made according to the case is conveyed to the user through the man-machine interface, the user feeds back the success or failure information after the application of the result is eliminated to the system, if the diagnosis is successful, the diagnosis is finished, if the diagnosis is unsuccessful and other cases exist in the global database, the next case is qualified, and the like, if the obtained multiple results are invalid or no corresponding result is found, reasoning based on the fault manual diagnosis tree is carried out. As long as a case is qualified, whether the diagnosis is successful or failed, the self-learning machine will modify an attribute of the case according to the feedback result. The interpreter uses the route tracking method to track the diagnosis process so as to provide the user with the basis for the system to obtain the diagnosis result. Administrators with modify permissions can modify the contents of the knowledge base using the knowledge base manager. The expert system mainly consists of human-machine interface, knowledge base, global database, case-based reasoning subsystem, fault tree-based reasoning subsystem, reasoning mechanism, interpretation mechanism and learning mechanism. According to the goal of system construction, TCAS component-level fault diagnosis expert system structure block diagram as shown in fig. 2.

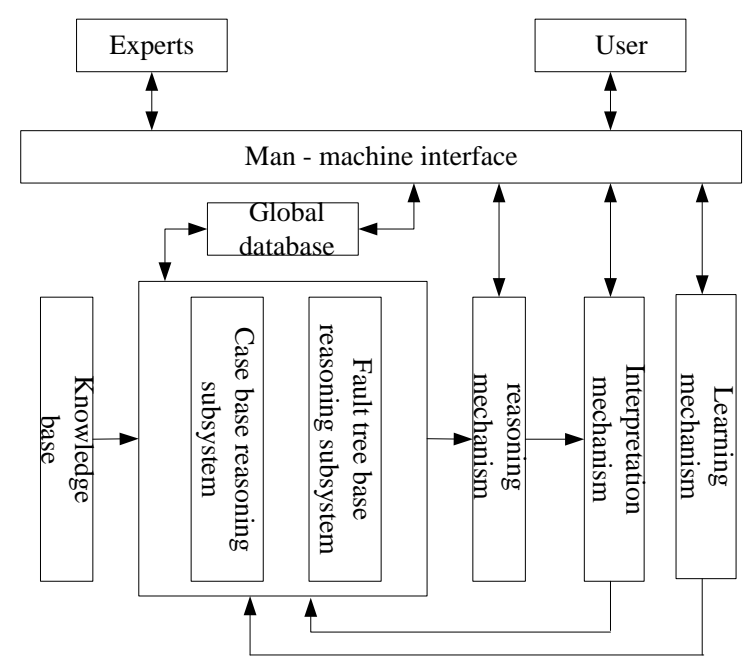

Fig. 2: TCAS component-level fault diagnosis expert system structure block diagram. 


\subsection{Knowledge Database Establishment}

The establishment of knowledge base is the central work of expert system. The knowledge base of expert system is built by integrating knowledge system into database management system, which makes database management system manage both knowledge base and database. Knowledge is stored in the database, and the knowledge base of fault diagnosis expert system is established by using the ability of efficient and organized management and storage of data in the database. And use the relational database to ensure the integrity of the data related knowledge to ensure the completeness of the expert knowledge. When designing expert knowledge base, it is necessary to combine the representation of knowledge with the design of tables in the database, and to consider the relationship model between tables and the need of programming application, so as to connect the fields in the tables with the parts contained in the knowledge representation method. The design structure diagram of expert system combining knowledge base and database is shown in fig. 3 .

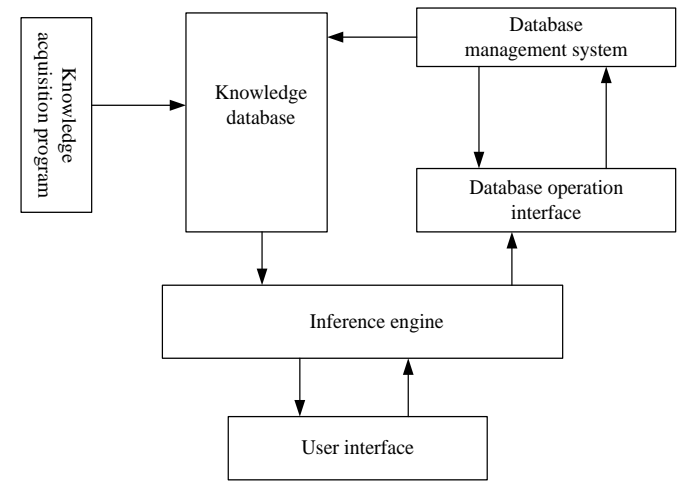

Fig. 3: Database building knowledge base structure diagram.

\subsection{Reasoning Diagnosis Mechanism}

Because case-based reasoning can only search for existing cases, the number of cases is limited and the phenomenon of surface similarity is easily regarded as essential similarity when matching, which leads to misdiagnosis. The inference based on fault tree can only use rules to infer the anticipation in advance. The explanation and countermeasure of the conclusion cannot adapt to the change of situation flexibly. Therefore, the expert system combines the two reasoning methods to achieve a comprehensive reasoning strategy based on case and fault tree, which can make full use of knowledge and give full play to the advantages of various reasoning methods to find the solution to the problem.

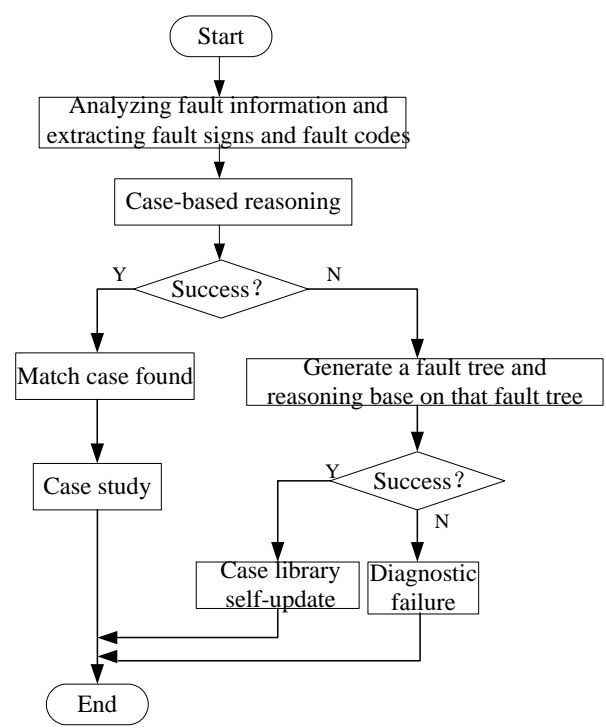

Fig. 4: Integrated reasoning flow chart. 
The specific reasoning flow chart of inference engine is shown in fig. 4. Fault symptom and fault code are obtained by extracting characteristic data. Firstly, case library is retrieved. If matching cases are found in case library, system learning is started, and parameters are adjusted, such as the modification of confidence degree. If no exactly matched case or multiple cases are found available, the system generates a fault tree by combining the fault symptom and the fault code, and executes a fault tree-based reasoning process.

\section{Analysis of TCAS Processor Diagnostic Results}

In order to verify the correctness and effectiveness of TCAS component-level fault diagnosis expert system, the system needs to be further verified. The specific verification method comprises the following steps: a group of faults which have been encountered in maintenance of TCAS board cards are proposed by field experts, and are solved by the expert system respectively according to the phenomena of the faults, and the obtained results are compared and analyzed with the actual fault diagnosis experience of the experts so as to complete the verification of the system. Table 1 shows a comparison of the troubleshooting results (in part) between domain experts and expert systems.

Table 1: Field expert and expert system fault diagnosis results (part) comparison table

\begin{tabular}{|c|c|c|c|c|c|}
\hline \multirow[b]{2}{*}{$\begin{array}{c}\text { Fault } \\
\text { number }\end{array}$} & \multirow[b]{2}{*}{$\begin{array}{c}\text { Fault } \\
\text { phenomenon }\end{array}$} & \multicolumn{2}{|c|}{ Expert system fault diagnosis } & \multicolumn{2}{|c|}{ Domain expert fault diagnosis } \\
\hline & & $\begin{array}{l}\text { Qualification case fault } \\
\text { location (confidence) }\end{array}$ & $\begin{array}{c}\text { Troubleshooting } \\
\text { scheme }\end{array}$ & Expert opinion & $\begin{array}{c}\text { Actual } \\
\text { troubleshooting } \\
\text { measures }\end{array}$ \\
\hline 1 & $\begin{array}{c}\text { U2: } \\
\text { 74FCT245Chip } \\
\text { unidirectional } \\
\text { failure }\end{array}$ & $\begin{array}{l}\text { 1. } 74 \text { FCT } 245 \text { circuit } \\
\text { connection short circuit } \\
\text { or open circuit }(0.9) \\
\text { 2. chip pin damage }(0.1)\end{array}$ & $\begin{array}{l}\text { Use a multi- } \\
\text { meter to test the } \\
\text { resistance } \\
\text { between the } \\
\text { power pin of the } \\
\text { chip and ground }\end{array}$ & $\begin{array}{l}\text { 1.circuit } \\
\text { connection } \\
\text { short circuit or } \\
\text { open circuit } \\
\text { 2.chip pin } \\
\quad \text { damage } \\
\end{array}$ & $\begin{array}{l}\text { Test the } \\
\text { resistance } \\
\text { between the } \\
\text { power pin of } \\
\text { the chip and } \\
\text { ground }\end{array}$ \\
\hline 2 & $\begin{array}{c}\text { TCAS processor } \\
\text { selection } \\
\text { No.2ATC } \\
\text { transponder } \\
\text { failure }\end{array}$ & $\begin{array}{l}\text { 1.No.2ATCtransponder } \\
\text { damage }(0.6) \\
\text { 2.TCAS processor up and } \\
\text { down two directional } \\
\text { antenna damage }(0.3) \\
\text { 3.coaxial cable fault }(0.1) \\
\text { connecting TCAS to } \\
\text { No.2ATC transponder to } \\
\text { suppress signal }\end{array}$ & $\begin{array}{c}\text { Replace } \\
\text { No.2ATC } \\
\text { transponder }\end{array}$ & $\begin{array}{l}\text { 1.No.2ATC } \\
\text { transponder is } \\
\text { damaged } \\
\text { 2. the upper } \\
\text { and lower } \\
\text { directional } \\
\text { antennas of } \\
\text { TCAS } \\
\text { processor are } \\
\text { damaged }\end{array}$ & $\begin{array}{c}\text { Replace } \\
\text { No.2ATC } \\
\text { transponder }\end{array}$ \\
\hline
\end{tabular}

Table 1 lists and compares the diagnostic results of two more representative actual failures presented by domain experts. It can be seen that:

(1) The expert system to consider the cause of the fault is comprehensive. In the diagnosis of fault 2 , although the expert and expert system agree that No.2ATC transponder failure is the most likely, but for the rest of the possible fault location, experts do not consider the TCAS and No.2ATC suppression signal coaxial cable fault problem. This is because the expert system diagnosis is based on a combination of a large number of flight records, fault diagnosis literature, consult a number of experts in the field of experience, and therefore more comprehensive.

(2) The idea of fault diagnosis in this system is similar to that of domain experts, which is based on the magnitude of component fault confidence, and has high reliability. After verification, the expert system achieves the basic purpose and requirements of the design.

\section{Conclusions}

This paper mainly studies the component-level fault diagnosis expert system of TCAS processor. This paper takes TCAS processor board as the diagnosis object, based on the in-depth summary and analysis of the research results at home and abroad, in the aspect of knowledge database establishment, puts forward a kind of knowledge expression mode for comprehensive fault intelligent diagnosis system. The knowledge 
base of this system is different from the rule base of traditional expert system. According to the different characteristics of case-based reasoning and fault tree-based reasoning, it uses the framework method to express knowledge, thus constructing the knowledge base of this expert system. In the aspect of reasoning diagnosis, case-based reasoning and fault tree-based reasoning are combined, and the reasoning mechanism of comprehensive reasoning is put forward and applied to the system, which improves the diagnosis efficiency of the system, can find the solution of the problem to the greatest extent, and achieves the purpose and expected effect of component-level fault diagnosis of the expert system.

\section{Acknowledgements}

This work was supported by Special Funding Project of China Postdoctoral Science Foundation (2014T70967), Education and teaching research project of Anhui education department (2016jyxm0489), Innovative training program for college students in Anhui province (AH201612216034, AH201612216033), Natural Science Research Key Project of Anhui Province Higher School (KJ2017A630), Quality Engineering Project of Anhui Provincial (2016jxtd055), Key Construction Discipline Project at College Level of Anhui Xinhua University (zdxk201702), Institute Project at College Level of Anhui Xinhua University (yjs201706).

\section{References}

[1] W. G. Fenton, T. M. McGinnity, L. P. Maguire, "Fault Diagnosis of Electronic Systems using Intelligent Techniques: A Review", IEEE Transactions on Systems, Man, and Cybernetics-Part C: Applications and Reviews, August 2001, pp. 269-281.

[2] Billy Fenton, T. M. McGinnity, L. P. Maguire, "Fault Diagnosis of Electronic Systems using Artificial Intelligence", IEEE Instrumentation and Measurement Magazine, September 2002, pp. 16-20.

[3] Cai, Z., John, D., Gong, T. Advanced Expert Systems: Principles, Design and Applications. Science Publication, Beijing, 2005.

[4] Cao, S., He, Z.: Application of Expert System Based on Artificial Neural Network. Tactical Missile Control Technology (1), 2007.

[5] Feng, L., Li, J., et al. Design and Implementation For Gas Turbine Fault Diagnosis Expert System. Journal of UEST of China 29(3), 2006.

[6] Zhang, E.W.Y., Tor, S.B., Britton, G.A., Deng, Y.-M. EFDEX: A Knowledge-Based Expert System for Functional Design of Engineering Systems. Int. Journal of Advanced and Manufacturing Technology 17, 339-353, 2001.

[7] Sheremetov, L.B., Contreras, M., Valencia, C. Intelligent Multi-agent Support for the Contingency Management System. Expert Systems with Applications 26(1), 57-71, 2004.

[8] Avci, D., Varol, A. An expert diagnosis system for classification of human parasite eggs based on multi-class SVM. Expert Systems with Applications 36(1), 43-48, 2009. 